\title{
A history of penile implants
}

\author{
Katherine M. Rodriguez ${ }^{1}$, Alexander W. Pastuszak ${ }^{2,3}$ \\ ${ }^{1}$ Baylor College of Medicine, Houston, TX, USA; ${ }^{2}$ Center for Reproductive Medicine, ${ }^{3}$ Scott Department of Urology, Baylor College of Medicine, \\ Houston, TX, USA \\ Contributions: (I) Conception and design: All authors; (II) Administrative support: All authors; (III) Provision of study materials or patients: All \\ authors; (IV) Collection and assembly of data: All authors; (V) Data analysis and interpretation: All authors; (VI) Manuscript writing: All authors; (VII) \\ Final approval of manuscript: All authors. \\ Correspondence to: Alexander W. Pastuszak, MD, PhD. Assistant Professor, Center for Reproductive Medicine, Baylor College of Medicine, 6624 \\ Fannin St., Suite 1700, Houston, TX 77030, USA. Email: pastusza@bcm.edu.
}

\begin{abstract}
Erectile dysfunction (ED) has long been described by physicians and patients, with treatments for ED proposed starting in the $8^{\text {th }}$ century BC. In the last 50 years, however, there have been many advances in medical and surgical management of ED, notably the introduction of the inflatable penile prosthesis (IPP) in 1973 and phosphodiesterase type 5 inhibitors (PDE5Is) in 1998. Here we review the evolution of the IPP from 1973 through the current day. The 3-piece device was first described in 1973 by Dr. F. Brantley Scott, who helped found American Medical Systems (AMS) to market and sell the device. In 1983, Mentor (now Coloplast) started marketing a competing device. AMS and Mentor have made multiple modifications to the device over the years, which have increased rigidity, durability and patient satisfaction, and have decreased surgical variability, post-operative infection and spontaneous inflation. Today, the IPP is a safe and effective option for many men who have failed medical therapies, with high satisfaction from both patients and partners.
\end{abstract}

Keywords: Penile prosthesis; erectile dysfunction (ED); penile implants

Submitted Mar 05, 2017. Accepted for publication Apr 01, 2017.

doi: $10.21037 /$ tau. 2017.04.02

View this article at: http://dx.doi.org/10.21037/tau.2017.04.02

\section{Introduction}

Erectile dysfunction (ED), the inability to achieve or maintain an erection sufficient for sexual performance, has been described for centuries. ED has numerous psychological and social implications, can diminish selfesteem and quality of life, and can negatively impact female partner sexual function (1). The first accounts of ED treatment come from medieval Islamic physicians in the $8^{\text {th }}$ century $\mathrm{BC}$ who tried herbs, prayer, topical and intraurethral treatments and multi-modality therapies with limited success. The treatment of ED has been of interest to physicians since then and has appeared in historical documents such as The Canon of Medicine and The Comprehensive book on Medicine (2,3). Accounts of ED also appear in the Old Testament as well as in sacred Hindu texts. Hippocrates famously declared that being worried about business and unattractive women caused ED (4).

Today, it is estimated that as many as $52 \%$ of men between the ages of 40-70 experience some degree of ED (5). ED has many etiologies that can be divided into organic and psychological categories. Psychological causes of ED include depression, anxiety, relationship trouble, and past history of sexual abuse, among others. Organic etiologies of ED are most commonly vascular or mechanical. Many chronic conditions including hypertension, metabolic syndrome, diabetes, smoking and hypercholesterolemia can contribute to a vascular cause of $\mathrm{ED}$, and are also associated with coronary artery disease, to which ED is inextricably linked (6). Lastly, men with penile injury, Peyronie's disease, spinal cord injuries or testosterone deficiency can also experience ED (7).

Over the past 3 decades, many novel, effective therapies to treat $\mathrm{ED}$ have been implemented, most notably 
phosphodiesterase type 5 inhibitors (PDE5Is). While PDE5Is are certainly effective, more than $30 \%$ of ED patients fail treatment with these medications (8). However, other ED treatment options exist, including intracavernosal injections and vacuum erectile devices. For men who fail all medical therapies, surgical implantation of an inflatable penile prosthesis (IPP) should be considered, and represents a safe and highly effective ED treatment. Penile prostheses were first used to treat ED in the early 1970s, but both the devices as well as the surgical implantation techniques have evolved over the last 40 years.

\section{The evolution of surgical treatment for ED}

Surgical and medical treatments for ED have been trialed for many centuries. The first of these primitive attempts included increasing testosterone levels by injecting testicular tissue (4). This came from the observation that there was a substance in the testicles that warded off ED and the loss of vitality. The famous physiologist and neurologist Charles-Edouard Brown-Sequard reported in 1889 that injecting himself with dog testicle extract successfully increased his energy levels (4). In the 1800s, physicians attempted injections of sheep testicles after anecdotally observing a link between a testicular substance and ED (2). The first attempt at testicular transplantation was in 1918 when the Russian surgeon Serge Voronoff published that transplanting monkey testicular interstitial cells could "renew youth". Many similar trials were performed in the United States where Victor Lespinasse, a professor of genitourinary surgery at Northwestern University, found transient success in transplanting cadaveric testicles, stripped of the tunica vaginalis and epididymis, and sectioned into 1-mm slices, into the abdominal muscles of impotent recipients (4). Physicians, realizing that ED could result from abnormal blood flow, attempted dorsal penile vein ligation and in 1902, Wooten attempted the first vascular surgery for ED, though this was unsuccessful (9). The first successful surgical intervention for ED was performed in 1935 by O. S. Lowsley. In what is believed to be the first penile plication procedure, he applied observations from his work with dogs and plicated the ischiocavernosus muscle and shortened the bulbospongiosus muscles of human male penises. He noted success and patient satisfaction over 10 years but cautioned that this procedure was for a specific patient population, namely men with a traumatic etiology of ED (10).

\section{The advent of penile implants}

Subsequent attempts were made at creating penile prosthetics, initially directed to treating penile trauma and acting as a conduit for urine. There are records of penile prostheses dating to the $16^{\text {th }}$ century when Ambroise Paré fashioned a penis out of wood for urination in a traumatic penile amputation patient (11). The first modern attempt at penile reconstruction was attempted in the 1930s and was merely a conduit for urination (4). NA Borgus, a German physician, is widely considered the first to engineer a prosthesis in 1936 that functioned for both micturition and intercourse. He used rib cartilage, designed to function like the os penis of mammals with less well-developed erectile tissue than humans, on soldiers with traumatic amputation injuries of the penis, utilizing tissue expanding techniques to create a pocket for placement of the prosthetic (12). This was improved upon in 1944 by AP Frumkin, a Soviet surgeon who published an article on his surgical technique. Initially, a flap from abdominal skin was fashioned into a tube, followed by placement of cartilage harvested from the patient's $8^{\text {th }}$ or $9^{\text {th }}$ rib into the new cavernous bodies. About 3 to 4 weeks later, the tube was divided to create a penis and a urethra was fashioned. Despite these attempts, this procedure was fraught with many complications and was often only effective for 18 months to 4 years, when the cartilage would fold on itself or be absorbed by the body $(4,12)$.

American physician Dr. Peter L. Scardino is most likely the first to use a synthetic implant but his work was never published. Thus, Willard E. Goodwin and William Wallace Scott are credited with placement of the first acrylic penile implants in 1952 (11). Many advances in surgical technique and materials during the 1960s and 1970s, including the use of silicone as a surgical material facilitated the rise of inflatable penile implants. Dr. GE Beheri, an Egyptian surgeon, was the first to use intracavernosal polyurethane rods placed within the tunica albuginea after dilation. This approach was successful and Dr. Beheri performed over 700 procedures. The new material bettered the results and lessened side effects but because Dr. Beheri was a plastic surgeon and published in plastic surgery journals, the procedure did not gain significant traction in the urologic community $(11,13-15)$. The last development in technology that led to the current IPP can be credited to the National Aeronautics and Space Administration (NASA), which developed a high-grade silicone as part of the space program that was subsequently used by American doctors 
for penile implants. A silicone implant was first tried by RO Pearman when he placed it between Buck's fascia and the tunica albuginea, but was ultimately unsuccessful because of significant post-operative pain. Subsequent placement within the tunica albuginea, much like the work of Beheri, was successful. These advances all eventually led to the development of the precursor to the contemporary IPP, developed by F. Brantley Scott, a urologist at Baylor College of Medicine, and introduced in 1973 (11,16).

\section{The evolution of the modern IPP}

In 1974, just a year after Dr. Scott's revolutionary inflatable device, was introduced to the market, Drs. Michael Small and Hernan Carrion introduced their competitor device: a precursor to semirigid malleable devices that are popular in other parts of the world. The device consisted of two sponge-filled, silicone-covered rods. After the initial semirigid malleable device was introduced, other devices also became available. Notably, the Jones-ESKA silicone prosthesis, silver prosthesis, Mentor Accuform prosthesis, and the AMS 600 all were introduced during the 1980 s $(17,18)$. While improved versions of these devices are used in other countries, the semirigid devices do not allow for a natural appearing flaccid state and are infrequently used in the United States $(11,19,20)$.

The original design of the IPP included two inflatable silicone rods, a welcome departure from previous semirigid designs. In his initial description in July 1973, Dr. Scott described his device as composed of two inflatable silicone bodies, a reservoir and a control pump. Through a series of four case reviews of his first five patients, Dr. Scott laid the groundwork for a very promising, long-term solution for ED $(11,21)$. Dr. Scott marketed the first generation of IPPs through AMS, a company that he helped found. Though initially referred to as the inflatable penile implant, when AMS began marketing the device, the name was changed to the AMS $700(11,15)$. Like most first iterations of a device, initial design problems became apparent with use, most of which have been remedied over the last 40 years (see Table 1).

\section{Initial AMS devices}

The first version of the IPP suffered from suboptimal device lifetimes and rigidity, with a $61 \%$ complication or revision rate at 3-11 years after placement (22). Changes to the initial design of the AMS 700 between 1983-1987 included placement of caps on both ends of the cylinders and the development of a suture-less fluid containment system, which decreased inter operator variability in preventing leaks (23). A major advance came in 1986 when kinkresistant tubing (KRT) was added, permitting less precise intraoperative measurements and simplifying the insertion procedure. Polytetrafluoroethylene (PTFE) sleeves were also added to increase the durability and lifespan of the device, and to prevent adhesion to the corporal tissues. While more durable, the filling of the sleeves was restricted by the patient's corpus cavernosum and therefore resulted in aneurysmal dilation. In 1987, the PTFE sleeves were replaced by a multilayer design. This 3-ply system in the new AMS $700 \mathrm{CX}^{\circledast}$ used both an inner silicone coating and a woven silicone layer that allowed for reduced friction and easier inflation, reducing resistance to filling that had previously led to dilation $(11,16,21)$. These alterations to the device improved the procedure dramatically; the $61 \%$ complication rate in patients operated on before 1983 was reduced to only $13 \%$ for those who received an AMS 700 after 1983 (23,24). The AMS 700CX was again evaluated in 2000 when Carson et al. found that in 372 patients the mechanical reliability of the device was $86.2 \% \pm 4.6 \%$ after 5 years with infection in $3.2 \%$ of patients $(23,25)$. In 2000, AMS debuted a parylene coating that further dramatically reduced friction, better mimicking an organic erection $(11,26)$.

The pump of the AMS 700 has also been a target for improvement. AMS updated their pump design with the momentary squeeze (MS) pump. The pump contains a oneway valve that requires squeezing the deflate button for 3-4 s to activate, and prevents unintentional inflation (23). AMS also now makes several models of IPP cylinders for use on men with smaller phalluses (AMS $700 \mathrm{CXM}^{\circledR}$ requiring $11 \mathrm{~mm}$ dilation) or other anatomical abnormalities such as fibrosis (AMS $700 \mathrm{CXR}^{\circledR}, 9 \mathrm{~mm}$ dilation) that previously were a challenge to place a device in $(16,23,27)$. There has been interest in increasing penile length and girth since the advent of the IPP, and the AMS Ultrex (now LGX ${ }^{\circledR}$ ) had an expandable middle layer but was ultimately unsuccessful because of poor material reliability and durability, with a resulting suboptimal device performance. Furthermore, the Ultrex was not as effective in patients with anatomic disease such as Peyronie's disease and the preferred device for these patients is its predecessor, the AMS CX/CXR ${ }^{\circledR}(28,29)$. AMS's second attempt at a prosthesis that could expand in both length and girth was the AMS LGX ${ }^{\circledR}$, which allowed a $25 \%$ increase in penile length and girth (27). While AMS 
Table 1 Summary of penile prostheses

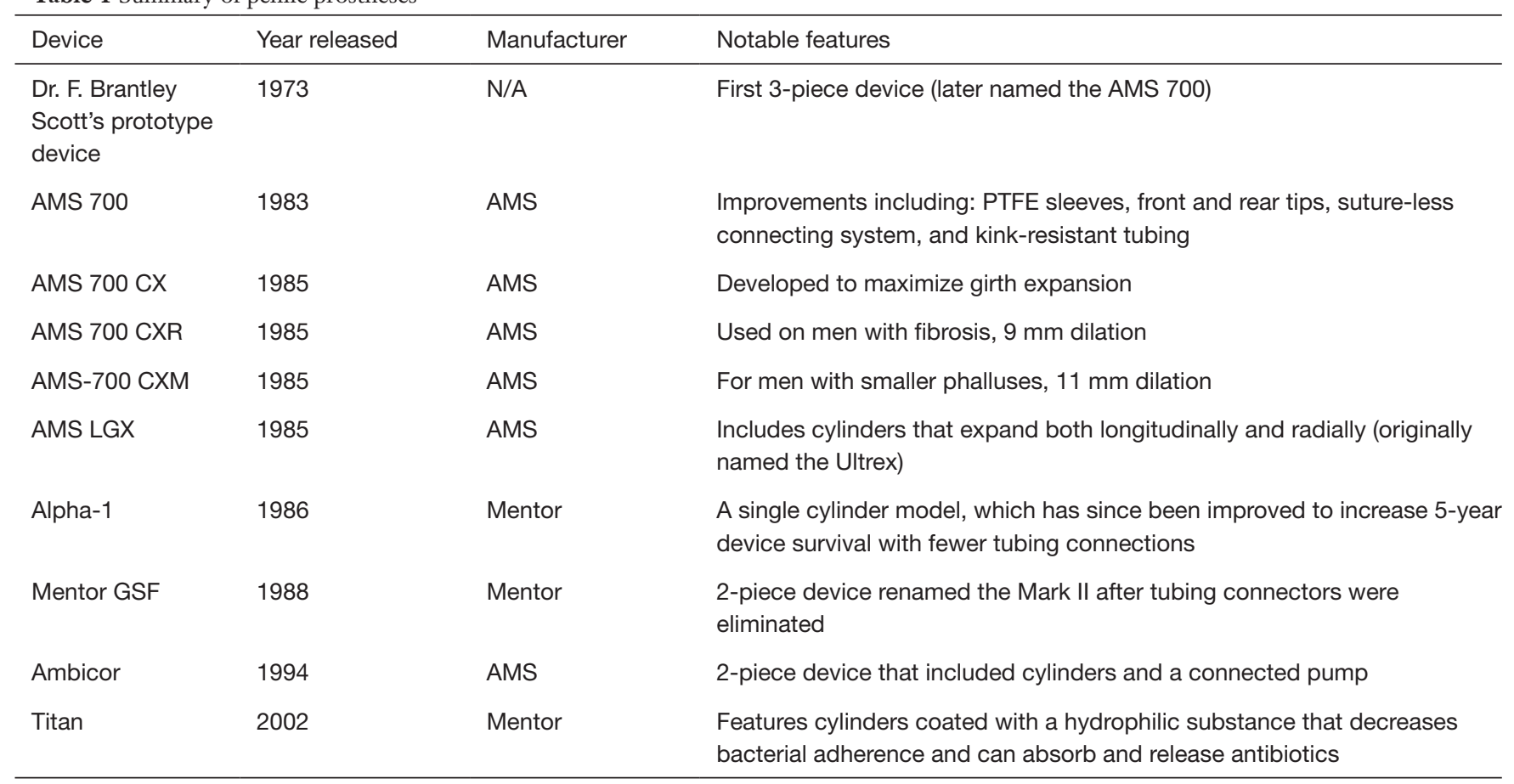

AMS, American Medical Systems; PTFE, polytetrafluoroethylene.

was the first company to market IPP, the market changed in 1983 when Mentor (now Coloplast) entered the arena.

\section{Mentor devices}

The most significant modification that the Mentor company made to the 3 -piece IPP system was the use of different materials from the AMS IPP models. Rather than using silicone, the Mentor device cylinders were initially made from polyurethane. Later, Mentor patented the Bioflex ${ }^{\circledR}$ material $(30,31)$. Bioflex ${ }^{\circledR}$ had many advantages over silicone cylinders, with perhaps the most significant being a 7 -fold higher tensile strength, while maintaining biocompatibility. Bioflex ${ }^{\circledR}$ also had a more limited ability to expand, in contrast with silicone models that were prone to excessive dilation (31). Shortly after the introduction of Bioflex ${ }^{\circledR}$, Mentor added a Bioflex ${ }^{\circledR}$ reservoir connected using silicone KRT $(11,16,31,32)$. The Bioflex ${ }^{\circledR}$ IPP models have demonstrated impressive long-term durability, with $88 \%$ of devices functional after 10 years of use $(11,23)$. In 1987, Mentor unveiled an updated model that included a modified pump, the addition of nylon to improve the KRT, and caps on the rear tip extenders to improve durability $(16,32)$. In 1986, Mentor introduced a single cylinder model, the
Alpha-1 IPP, which further improved device durability and reduced the risk of the tubing leakage as a result of fewer tubing connectors. The Alpha-1 also had higher 5-year survival rates compared to models manufactured before November 1992 [92.6\% vs. 75.3\% respectively $(\mathrm{P}<0.0001)$ ], and lowered failure rates $[1.3 \%$ vs. $5.6 \%$ respectively $(\mathrm{P}<0.0001)](33)$.

\section{IPP enhancements since 1990}

In 1993, AMS further improved the 700 Ultrex IPP by strengthening the middle fabric layer after reports of tears by adding a stronger fabric weave $(23,28)$. This modification was studied in 2000 when a group from the Cleveland Clinic compared patients who received the original and enhanced implant (85 and 52 patients, respectively). The 5-year Kaplan-Meier estimates of overall device survival were $64.7 \%$ in the original devices and $77.7 \%$ in the enhanced devices $(\mathrm{P}=0.23)$. Mechanical device survival at 5 years was $70.7 \%$ for the original and $93.7 \%$ for the enhanced device $(\mathrm{P}=0.017)$, and cylinder survival was $80.2 \%$ and $96.2 \%$ for the two groups, respectively $(\mathrm{P}=0.008)$ (27). In 1988, Mentor released the Mentor GSF prosthesis, a 2-piece device later renamed the Mark II 
after tubing connectors were eliminated from the design. The most recent 2-piece design produced by Coloplast is the Excel model, which is only used outside the United States (34). In 1994, AMS released Ambicor IPP, a 2-piece device that included cylinders and a connected pump. While the placement procedure using these devices was shorter because there was no reservoir to place, the devices did not inflate as well without a reservoir to store additional fluid, and did not achieve the rigidity of three piece IPPs (23).

In 2000, Mentor introduced the lock-out valve, designed to stop IPP auto-inflation resulting from increased intraabdominal pressure. Before the introduction of the lockout valve, auto-inflation was reported in $11 \%$ of cases, with $2 \%$ requiring surgical revision. While generally a benign problem, auto-inflation can cause embarrassment and inconvenience, and in rare cases can cause device breakdown (35). In 2002 Wilson et al. compared devices with and without lock-out valves. While there was no significant increase in Kaplan-Meier estimated 1-year device survival, patient satisfaction, infection or mechanical failure, only 2 patients $(1.3 \%)$ with devices equipped with lock-out valves reported auto-inflation compared to $11 \%$ of patients without these valves (36). AMS started offering antibiotic coated devices in 2000 with its InhibiZone ${ }^{\mathrm{TM}}$ coating, composed of minocycline and rifampin. In 2004 Carson et al. retrospectively compared coated and uncoated devices, and found that the incidence of infection after 60 days was only $0.28 \%$ in the InhibiZone group, but $1.59 \%$ in the control group $(\mathrm{P}=0.0034)$, demonstrating a $82.4 \%$ reduction in infection rate in IPPs treated with InhibiZone ${ }^{\mathrm{TM}}$. At 180 days, the infection rates in the treated and control groups were $0.68 \%$ and $1.61 \%$, respectively $(\mathrm{P}=0.0047)$, a $57.8 \%$ reduction in infection rates (37). In 2002 Mentor introduced another improvement with the goal of reducing postoperative infection rates-the $\operatorname{Titan}^{\circledR}$ — which had cylinders coated with a hydrophilic substance that decreases bacterial adherence and can absorb and release antibiotics. In a 2004 study by Wolter et al., Titan devices were observed to have a 1 -year infection rate of $1.06 \%$ across 2,357 patients, compared with a $2.07 \%$ infection rate seen in 482 patients implanted with alpha-1 devices. Staphylococcus bacterial species were the major infectious agent in both groups $(23,38)$. In 2011, Dhabuwala et al. compared Titan implants coated with vancomycin/gentamycin or rifampin/ gentamicin, and Inhibizone-impregnated (AMS) implants to examine rates of infection. The Titan implant with vancomycin/gentamycin had an infection rate of $4.4 \%$ and the Inhibizone implant had a rate of $1.3 \%(\mathrm{P}=0.05)$.
The Titans with rifampin/gentamycin had no infections reported. This suggests rifampin as the best antibiotic to be used (39). In 2006, the Mentor company was purchased by Coloplast, which allowed Coloplast to expand into men's urologic health.

\section{Evolution of operative techniques}

Implantation techniques for penile prostheses have undergone numerous iterative improvements as devices have become more durable and reliable. Both AMS and Coloplast IPPs offer variably colored tubing to facilitate identification of connections between cylinders, pump, and reservoir. The Scott retractor and hooks facilitate device placement, and the Furlow introducer and Keith needle further simplify the procedure by facilitating cylinder placement $(11,24)$. Carrion-Rossello cavernotomes now permit gradual dilation of fibrotic corpora, decreasing the risk of perforation (40). As physicians have become more skilled at IPP placement, alternative reservoir sites have been introduced. In most cases, the reservoir is placed retroperitoneally in the space of Retzius. However, in the setting of prior surgery or concern for trauma to intraabdominal organs, alternative reservoir placement sites have grown in popularity. Today, IPP reservoirs can be placed ectopically, between the transversalis fascia and rectus muscle (41). Reservoir design has followed suit, with AMS introducing its flattened Conceal ${ }^{\circledR}$ reservoir in 2006 and more recently, Coloplast unveiled the Cloverleaf ${ }^{\circledR}$ reservoir $(11,42)$.

\section{Limitations to penile prosthetics}

While penile prosthetics have come a long way since 1973, there remain numerous limitations and areas for improvement. Only $5 \%$ of eligible patients undergo IPP placement, for reasons including expense, fear of surgery or complications, and that having to inflate and deflate the device feels unnatural $(11,43)$. Compared to other ED treatment modalities, IPP requires more down time after placement and carries the risk of infection and anesthesia complications, like any other surgical procedure. Another limitation that has received attention from the media in the last 10 years is cost, and who should pay for these devices. Currently, devices range in price from $\$ 8,000-\$ 14,000$, with coverage by Medicare. One of the major limitations to IPPs is comfort. In 2013, Hakky et al. created 3D models of human cadaveric corpora cavernosa and compared them 
to two different models of Coloplast Titan IPPs to assess how well the device mimicked the natural penile anatomy. They found subtle differences in shape, especially at the distal end of the device. This is an area of ongoing research and remains a limitation of current IPPs $(44,45)$. As microbial resistance continues to emerge, the IPP will need to continue evolving to stay ahead of complication postoperative infections.

\section{Conclusions}

Penile prostheses as a treatment for ED have come a long way since $8^{\text {th }}$ century BC spiritual and herbal approaches. From the original malleable implants, to the modern inflatable 3-piece prosthetics with durable, reliable fluid systems and integrated infection control mechanisms, the device has significantly improved since the 1980s. With these iterative improvements have come a decrease in complication rates and an increase in patient satisfaction rates. While novel medical therapies for ED, such as gene therapy and treatments targeting novel erectile pathways hold promise, the IPP remains a durable, reliable, contemporary approach to successfully treating men with ED refractory to current medical therapies.

\section{Acknowledgements}

Funding: AW Pastuszak is a K12 scholar supported by a Male Reproductive Health Research (MRHR) Career Development Physician-Scientist Award (Grant \#HD073917-01) from the Eunice Kennedy Shriver National Institute of Child Health and Human Development (NICHD) Program.

\section{Footnote}

Conflicts of Interest: The authors have no conflicts of interest to declare.

\section{References}

1. Fisher WA, Rosen RC, Eardley I, et al. Sexual experience of female partners of men with erectile dysfunction: the female experience of men's attitudes to life events and sexuality (FEMALES) study. J Sex Med 2005;2:675-84.

2. Mandal A. Impotence (Erectile Dysfunction) History. 2013. Available online: http://www.news-medical.net/ health/Impotence-(Erectile-Dysfunction)-History.aspx
3. Pastuszak AW, Lentz AC, Farooq A, et al. Technological Improvements in Three-Piece Inflatable Penile Prosthesis Design over the Past 40 Years. J Sex Med 2015;12 Suppl 7:415-21.

4. Gee WF. A history of surgical treatment of impotence. Urology 1975;05:401-5.

5. Feldman HA, Goldstein I, Hatzichristou DG, et al. Impotence and its medical and psychosocial correlates: results of the Massachusetts Male Aging Study. J Urol 1994;151:54-61.

6. Janjgava $\mathrm{S}$, Doliashvili T. Erectile dysfunction as a predictor of cardiovascular disease. Georgian Med News 2016;(261):36-41.

7. Raheem AA, Kell P. Patient preference and satisfaction in erectile dysfunction therapy: a comparison of the three phosphodiesterase-5 inhibitors sildenafil, vardenafil and tadalafil. Patient Prefer Adherence 2009;3:99-104.

8. Moncada I, Martinez-Salamanca JI, Allona A, et al. Current role of penile implants for erectile dysfunction. Curr Opin Urol 2004;14:375-80.

9. Molodysky E, Liu SP, Huang SJ, et al. Penile vascular surgery for treating erectile dysfunction: Current role and future direction. Arab J Urol 2013;11:254-66.

10. Lowsley OS, Cangelosi JT. Ten years experience with an operation for the cure of certain types of sexual impotence. South Med J 1946;39:67-9.

11. Le B, Burnett AL. Evolution of penile prosthetic devices. Korean J Urol 2015;56:179-86.

12. Carrion H, Martinez D, Parker J, et al. A History of the Penile Implant to 1974. Sex Med Rev 2016;4:285-93.

13. Martínez-Salamanca JI, Mueller A, Moncada I, et al. Penile prosthesis surgery in patients with corporal fibrosis: a state of the art review. J Sex Med 2011;8:1880-9.

14. Jonas $\mathrm{U}$. The history of erectile dysfunction management. Int J Impot Res 2001;13 Suppl 3:S3-7.

15. Wilson SK, Delk JR 2nd. Historical advances in penile prostheses. Int J Impot Res 2000;12 Suppl 4:S101-7.

16. Hakky TS, Wang R, Henry GD. The evolution of the inflatable penile prosthetic device and surgical innovations with anatomical considerations. Curr Urol Rep 2014;15:410.

17. Jonas U. Silicone-silver penis prosthesis (Jonas-Eska), long-term experiences. A critical assessment. Urologe A 1991;30:277-81.

18. Mulcahy JJ. The Development of Modern Penile Implants. Sex Med Rev 2016;4:177-89.

19. Small MP. Small-Carrion penile prosthesis. A new implant for management of impotence. Mayo Clin Proc 
1976;51:336-8.

20. Jonas U. Alloplastics in the Treatment of Erectile Dysfunction. In: Jonas U, Thon WF, Stief CG. editors. Erectile Dysfunction. Heidelberg: Springer Berlin Heidelberg, 1991:291-311.

21. Scott FB, Bradley WE, Timm GW. Management of erectile impotence. Use of implantable inflatable prosthesis. Urology 1973;2:80-2.

22. Wilson SK, Wahman GE, Lange JL. Eleven years of experience with the inflatable penile prosthesis. J Urol 1988;139:951-2.

23. Henry GD. Historical review of penile prosthesis design and surgical techniques: part 1 of a three-part review series on penile prosthetic surgery. J Sex Med 2009;6:675-81.

24. Wilson SK, Delk JR 2nd. Historical advances in penile prostheses. Int J Impot Res 2000;12 Suppl 4:S101-7.

25. Carson CC, Mulcahy JJ, Govier FE. Efficacy, safety and patient satisfaction outcomes of the AMS 700CX inflatable penile prosthesis: results of a long-term multicenter study. AMS 700CX Study Group. J Urol 2000;164:376-80.

26. Kuyava CC. Parylene-coated components for inflatable penile prosthesis. U.S. Patent No. 6,558,315. 6 May 2003.

27. Milbank AJ, Montague DK, Angermeier KW, et al. Mechanical failure of the American Medical Systems Ultrex inflatable penile prosthesis: before and after 1993 structural modification. J Urol 2002;167:2502-6.

28. Daitch JA, Angermeier KW, Lakin MM, et al. Long-term mechanical reliability of AMS 700 series inflatable penile prostheses: comparison of CX/CXM and Ultrex cylinders. J Urol 1997;158:1400-2.

29. Montague DK, Angermeier KW, Lakin MM, et al. AMS 3-piece inflatable penile prosthesis implantation in men with Peyronie's disease: comparison of CX and Ultrex cylinders. J Urol 1996;156:1633-5.

30. Merrill DC. Mentor inflatable penile prosthesis. Urology 1983;22:504-5.

31. Hackler RH. Mentor inflatable penile prosthesis: a reliable mechanical device. Urology 1986;28:489-91.

32. Brooks MB. 42 months of experience with the Mentor inflatable penile prosthesis. J Urol 1988;139:48-9.

33. Wilson SK, Cleves MA, Delk JR 2nd. Comparison of mechanical reliability of original and enhanced Mentor Alpha I penile prosthesis. J Urol 1999;162:715-8.

Cite this article as: Rodriguez KM, Pastuszak AW. A history of penile implants. Transl Androl Urol 2017;6(Suppl 5):S851S857. doi: 10.21037/tau.2017.04.02
34. Simmons M, Montague DK. Penile prosthesis implantation: past, present and future. Int J Impot Res 2008;20:437-44.

35. Kobayashi K, Hisasue S, Shimizu T, et al. Erosion of an inflatable penile prosthesis due to autoinflation. Hinyokika Kiyo 2004;50:515-7.

36. Wilson SK, Henry GD, Delk JR Jr, et al. The mentor Alpha 1 penile prosthesis with reservoir lock-out valve: effective prevention of auto-inflation with improved capability for ectopic reservoir placement. J Urol 2002;168:1475-8.

37. Carson CC 3rd. Efficacy of antibiotic impregnation of inflatable penile prostheses in decreasing infection in original implants. J Urol 2004;171:1611-4.

38. Wolter CE, Hellstrom WJ. The hydrophilic-coated inflatable penile prosthesis: 1-year experience. J Sex Med 2004;1:221-4.

39. Dhabuwala C, Sheth S, Zamzow B. Infection rates of rifampin/gentamicin-coated Titan Coloplast penile implants. Comparison with Inhibizone-impregnated AMS penile implants. J Sex Med 2011;8:315-20.

40. Mooreville M, Adrian S, Delk JR 2nd, et al. Implantation of inflatable penile prosthesis in patients with severe corporeal fibrosis: introduction of a new penile cavernotome. J Urol 1999;162:2054-7.

41. Tausch TJ, Mauck R, Zhao LC, et al. Penile prosthesis insertion for acute priapism. Urol Clin North Am 2013;40:421-5.

42. Morey AF, Cefalu CA, Hudak SJ. High submuscular placement of urologic prosthetic balloons and reservoirs via transscrotal approach. J Sex Med 2013;10:603-10.

43. Burnett AL. Erectile dysfunction management for the future. J Androl 2009;30:391-6.

44. Hakky, Tariq S. 3D Reconstruction of the Corpus Cavernosum with Comparative 3D Analysis of the Titan vs AMS Inflatable Penile Prosthesis. Poster presented at: Middle eastern society of sexual medicine; 2013 November 14-16; Abu Dhabi, UAE.

45. Hakky TS, Ferguson D, Spiess PE, et al. Threedimensional mapping and comparative analysis of the distal human corpus cavernosum and the inflatable penile prosthesis. Asian J Androl 2013;15:567-70. 